\title{
HOUSEHOLD RESPONSES TO HEALTH RISKS AND SHOCKS: A STUDY FROM RURAL TANZANIA RAISES SOME METHODOLOGICAL ISSUES
}

\author{
MASHA F. SOMI ${ }^{1 *}$, , JAMES R. G. BUTLER ${ }^{1 \ddagger}$, FARSHID VAHID ${ }^{2}$, \\ JOSEPH D. NJAU ${ }^{3 \S}$ and SALIM ABDULLA ${ }^{3 \bullet}$ \\ ${ }^{1}$ Australian Centre for Economic Research on Health, Australian National University, Australia \\ ${ }^{2}$ School of Economics, Australian National University, Australia \\ ${ }^{3}$ Ifakara Health Research and Development Centre, Dar es Salaam, Tanzania
}

\begin{abstract}
The impact of a health shock (malaria) on household consumption patterns is investigated using a system of demand equations. After controlling for the overall levels of total expenditure by a household, the presence of a self-reported malarious individual in a household reduces consumption of luxury items and increases consumption of health care and products. Our results are compatible with the hypothesis that households behave strategically when coping with an illness related shock so as to minimise its impact on expenditure on necessities: if households need to re-allocate funds to health and health care products, they reduce consumption of luxury items. Copyright (C) 2009 John Wiley \& Sons, Ltd.
\end{abstract}

Keywords: household; consumption; health shock; malaria; Tanzania

\section{INTRODUCTION}

Households have limited resources to allocate to various expenditure items. When an individual within a household falls ill, some additional resources may be allocated to health related expenditure. The decisions around treatment seeking and its associated costs will

\footnotetext{
*Correspondence to: Masha F. Somi, Australian Centre for Economic Research on Health, Australian National University, Cnr Mills and Eggleston Roads, CANBERRA ACT 0200, Australia.E-mail: masha.somi@anu.edu.au ${ }^{\dagger}$ Visiting Fellow.

${ }^{\ddagger}$ Director.

${ }^{\S}$ Research Scientist (Health Economics).

'Senior Research Scientist (Epidemiology).
} 
have welfare impacts in the short- and long-run. These welfare impacts are likely to be shared across the whole household, rather than being borne by the ill individual alone (Sauerborn et al., 1996a). In the short-run, a bout of illness may cause households to substitute consumption away from other items (such as food) to health, whilst longer-run consequences include reduced investment in productive activities and increased vulnerability. Household behaviour during times of crisis, or unexpected shocks, has been explored in various settings. These studies have mostly focussed on household responses during famines, but some examples exist from the health literature (e.g. Sauerborn et al., 1996a and Nyamongo, 2002). These studies demonstrate that households behave strategically in order to minimise the impact of shocks on household welfare.

This paper aims to identify the impact of a health shock on short-run household welfare by exploring the relationship between the presence of a malarious/feverish individual within a household and household consumption patterns. Changing household budgets in order to fund health care is one potential strategy that households may employ to cope with an illness related shock. We are particularly interested in the impact of the presence of malarious/feverish individual on food consumption, given Coreil's (1983) study which found that some households were caught in a cycle of poor diet caused by high health expenditures, and high health expenditures caused by poor diets. Malaria was selected as the focus of the study because high economic burdens have been associated with the disease (Chima et al., 2003; Worrall et al., 2005).

\section{DATA AND METHODS}

\subsection{Study Area}

Over 96 per cent of Tanzania's population lives in areas of malaria risk (Roll Back Malaria, 2003), and it is the most commonly reported health complaint in the country (Government of Tanzania, 2001). The present study took place in 25 villages in the Kilombero and Ulanga Districts, Morogoro Region, southeastern Tanzania, under the umbrella of the Ifakara Demographic Surveillance Site (see INDEPTH, 2002). The most common occupations are subsistence farming, fishing and small scale trading. Rice and maize are the predominant food crops. The site has no paved roads, and some villages are cut off for parts of the year as a result of flooding. Most families have a second house at a farm, where they stay during the planting and harvesting seasons. Malaria transmission at the study site is intense and year round, with a mean entomological inoculation rate ranging between 79 and 1209 infective bites per person per year (Abdulla and Killeen, 2005).

\subsection{Data Collection}

Informed consent was obtained for all participating adults, and from parents or guardians of any children under the age of 11 years. Local and international ethics committees approved the study (ANUHREC 2003/269, IHRDC IRB 2004/97 and NIMR HRER/1049/ 2004). Household surveys were conducted on 554 households in the 25 study villages between September and December 2004. Six hundred households were randomly selected from 1295 that had participated in an earlier related data collection round, which was 
undertaken in collaboration with the Interdisciplinary Monitoring Project for Antimalarial Combination Therapy in Tanzania (IMPACT-Tz). ${ }^{1}$ During their interviews households provided information on their consumption patterns in the month before interview, using two recall periods: 1 month (for items such as clothes) and 1 week (for frequently purchased items such as food). Items for which data were collected with a 1 week recall period were multiplied by four to gain a monthly expenditure figure. The value of consumption of items produced within the home was imputed and included in the aggregate. Demographic information on household size and composition was collected to allow for the construction of household equivalence scales. Data on the prices of items purchased were collected so that, for analytical purposes, household consumption could be deflated to remove inter-household differences in prices and expressed as consumption per equivalent adult in the household. The method used for calculating household consumption followed the generally accepted method advocated by Deaton and Zaidi (1999). Consumption expenditure was categorised into six mutually exclusive and exhaustive groups: protein, other food, general household consumables, luxury items, health care and other. During interviews households also provided information on whether anyone in their household had experienced a bout of malaria or fever in the 2 weeks before interview. Fever, in the absence of runny nose or rash, is often used as a symptomatic diagnosis for malaria, particularly in highly endemic areas (Gove, 1997). This self-reported illness measure is used in surveys interested in the costs associated with malaria, given that it is the perception of illness that determines an individual's behaviour, particularly around treatment seeking (Mugisha et al., 2002). For analytical purposes, the malaria variable was included as a categorical variable $(0=$ no individual in the household has malaria, $1=$ at least one individual in the household has malaria).

\subsection{Data Analysis}

The association between a household's pattern of consumption and the presence of malaria in a household was investigated using two systems of demand equations. In the first system, absolute consumption per equivalent adult in the household in each of the six consumption categories was used as the dependent variable. In the second, the share of total consumption accounted for by each category was used as the dependent variable.

Given that the dependent variables in the equations are correlated (i.e. the amount spent on each consumption type is correlated with how much is spent on the other consumption types), the demand equations should be estimated as a system of equations rather than independent equations. However, since the same explanatory variables are used in all of the demand equations, these equations can be estimated separately using ordinary least squares (see, among others, Greene, 2003).

\footnotetext{
${ }^{1}$ The Interdisciplinary Monitoring Project for Antimalarial Combination Therapy in Tanzania (IMPACT-Tz) is a multiyear implementation research evaluation project that rests on a collaborative platform comprising the US Centres for Disease Control and Prevention (CDC), Ifakara Health Research and Development Centre, the National Institute for Medical Research, London School of Hygiene and Tropical Medicine (UK) and the Tanzanian Ministry of Health, including its National Malaria Control Programme, the Tanzania Essential Health Interventions Project and the Council Health Management Teams of Rufiji, Morogoro, Mvomeru, Kilombero and Ulanga Districts. IMPACT-Tz is primarily supported by funding from CDC, the United States Agency for International Development and Wellcome Trust.
} 
A number of alternative specifications of the relationship between consumption and malaria were investigated. The final specifications of the two demand systems are as follows:

$$
\begin{array}{cc}
C_{i}=\alpha_{0 i}+\alpha_{1 i} \mathrm{TC}+\alpha_{2 i} \mathrm{TC}^{2}+\alpha_{3 i} M+\varepsilon_{i} & (i=1, \ldots, 6) \\
S_{i}=\beta_{0 i}+\beta_{1 i} \mathrm{TC}+\beta_{2 i} \mathrm{TC}^{2}+\beta_{3 i} M+\eta_{i} \quad(i=1, \ldots, 6)
\end{array}
$$

where $C_{i}$ is household consumption per equivalent adult in category $i$, TC is total household consumption per equivalent adult, $S_{i}$ is the share of household consumption in category $i$ and $M$ is a categorical variable indicating the presence of malaria in the household $(0=$ no individual in the household has malaria, $1=$ at least one individual in the household has malaria). The square of TC is included as an explanatory variable to allow for nonlinear relationship between consumption and total expenditure. For example, a positive $\alpha_{1 i}$ and a negative $\alpha_{2 i}$ means that consumption of item $i$ increases with total consumption but a decreasing rate. Quadratic specification was used to capture such nonlinearities in preference to the more popular double-log specification because some households' consumption of some categories was zero.

The demand systems show the impact of malaria in a household on consumption and consumption shares in each consumption category controlling for the effect of interhousehold differences in total consumption. Several other household characteristics that potentially affect consumption and consumption shares (e.g. location of household) were included in alternative specifications of the demand systems but none were statistically significant and were excluded in the final specifications. Alternative coding of the malaria variable (a count of the number of self-reported individuals and a categorical variable including only children under the age of five) was also tested, but did not change the results. All statistical analyses were undertaken using Stata 9 (Stata Corp., College Station, Texas, USA). Satterthwaite's $t$-tests were used to determine if differences in average consumption between malarious and non-malarious groups were significant (Casella and Berger, 1990). The number of households living below the poverty line was determined by identifying those households where average consumption expenditure per equivalent adult was below US\$1 per day (or 28840 Tanzanian shillings per month).

\section{RESULTS}

Table 1 provides the descriptive statistics for the sample, including the number of households, the numbers and proportions of households which had experienced some malaria/fever and those which had sought treatment. A high proportion of households with

Table 1. Descriptive statistics for the sampled households

\begin{tabular}{lc}
\hline Number of households... & $N(\%)$ \\
\hline In the sample & $554(100)$ \\
With & $153(28)$ \\
$\quad-\quad$ at least one individual reporting malaria or fever & $32(6)$ \\
$\quad-$ more than one individual reporting malaria or fever & $141(25)$ \\
In which treatment was sought for malaria/fever & $447(81)$ \\
Living below the poverty line &
\end{tabular}


Table 2. Average consumption expenditure per equivalent adult and share of total, by expenditure type (Tanzanian shillings, 2004 prices)

\begin{tabular}{lcc}
\hline Expenditure group & $\begin{array}{c}\text { Average consumption } \\
\text { expenditure in the } \\
\text { month before interview }\end{array}$ & $\begin{array}{c}\text { Share of total } \\
\text { consumption } \\
\text { expenditure (\%) }\end{array}$ \\
\hline Food & 12565 & 57.2 \\
Protein & 1845 & 8.4 \\
General household consumables & 3783 & 17.2 \\
Luxury items & 2436 & 11.1 \\
Health care & 399 & 1.8 \\
Other & 929 & 4.2 \\
Total & $\mathbf{2 1 9 5 7}$ & $\mathbf{1 0 0}$ \\
\hline
\end{tabular}

Exchange rate: US\$ $1=1030$ Tanzanian shillings.

a malarious/feverish individual had sought treatment for the illness bout ( $n=141$ of 153 , 92 per cent).

Table 2 outlines the average consumption per equivalent adult in the month before interview by consumption type, and the average share of consumption that each type comprised of total expenditure. Food consumption comprised the majority of all household consumption.

Table 3 shows how average consumption (by consumption type) varies between households with/without at least one malarious individual. Households without an individual self-reporting malaria or fever spent significantly more on food, protein and luxury items, and significantly less on health care.

Whilst the bi-variate results in Table 3 suggest that malaria does have an effect on household consumption patterns, these results make no allowance for the effect of total household consumption on consumption in each category. Table 4 reports the findings from the multivariate analysis of the demand equations using actual consumption by type. After controlling for the level of total consumption by a household, the presence of a selfreported malarious individual in a household reduces consumption on luxury items and

Table 3. Expenditure patterns (average and proportion) by expenditure type and presence of a malarious individual in the household (Tanzanian shillings, 2004 prices)

Expenditure group

At least one individual in the household has selfreported malaria or fever

\begin{tabular}{lcc}
\cline { 2 - 3 } & \multicolumn{1}{c}{ Yes } & No \\
\hline Food & $11451(58 \%)$ & $12990(57 \%)^{1}$ \\
Protein & $1510(8 \%)$ & $1972(9 \%)^{1}$ \\
General household consumables & $3838(19 \%)$ & $3638(16 \%)$ \\
Luxury items & $1610(8 \%)$ & $2751(12 \%)^{1}$ \\
Health care & $565(3 \%)$ & $337(2 \%)^{1}$ \\
Other & $871(4 \%)$ & $952(4 \%)$ \\
Total & $\mathbf{1 9 8 4 5 ( 1 0 0 \% )}$ & $\mathbf{2 2 6 4 0 ( 1 0 0 \% )})^{1}$ \\
\hline
\end{tabular}

${ }^{1}$ Difference between Yes/No groups is significant at the $5 \%$ level of confidence. 


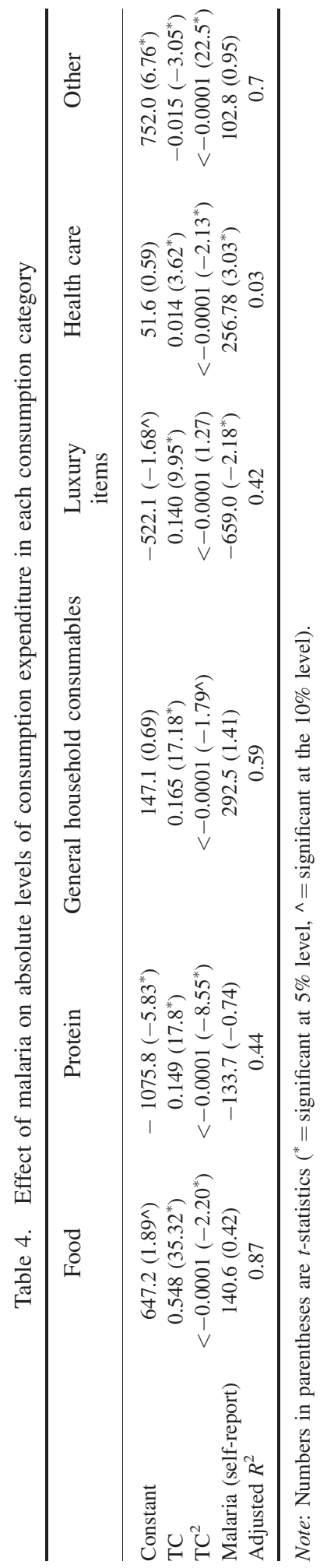


increases consumption on health care and health products such as medicines. The effect of self-reported malaria on consumption in the other four expenditure groups is not statistically significant.

Table 5 outlines the findings from the demand system equations using the share of total consumption each consumption type comprises. The results of these equations are similar to those from the actual consumption equations. In these equations, however, the effect of self-reported malaria on the budget share of luxury items is significant at the 10 per cent level of significance but not at the 5 per cent level. Interestingly, the budget share of health care is not affected by total household consumption.

\section{DISCUSSION}

The study aimed to identify whether the presence of a malarious individual in a household affects the way that households allocate resources to different consumption groups. Other things equal, households with at least one malarious individual consumed fewer luxuries but more health related products. The finding that the budget share of health care increased when an individual in a household self-reported malaria whilst the only other share that might decrease is the share of luxury items, is an indication that households behave rationally to keep the consumption of food and other necessities constant. This suggests that households are being strategic in order to minimise the impact of the health shock on their consumption of necessities. In other settings, short-run strategies such as use of savings, sale of assets, loans and requesting gifts from neighbours or family have been used by households in order to fund health care whilst maintaining consumption of other items (Sauerborn et al., 1996a). In Kenya and Tanzania, Eriksen et al. (2005) found that households often implemented several strategies at any one time in order to cope with a shock and that the short-run strategic responses that households employ to cope with shocks are components of an over-arching longer-run risk management strategy. In looking at household responses to famine, Corbett (1988) found that households living in areas prone to recurrent risk develop long-run strategies to minimise the impact of these risks, using the information available to them about their households situation, and the environmental and economic conditions. Household responses to shocks are thus planned rather than haphazard, and usually fall into a distinct sequence determined by the relative cost of each strategy: responses resulting in the lowest cost for the household are implemented first and those with the highest cost to the household last (Russell, 2005). Importantly, as households move along their sequence of strategies, their resilience and coping ability is increasingly eroded (Corbett, 1988). Note that the vast majority of households purchased health care as part of their response to illness, despite the fact that many people in the sample are very poor (81 per cent of individuals live on less than US\$ 1 per day). Whilst household decisions to shift consumption to health were not significantly associated with reduced consumption of other items, it is likely that even marginal shifts in those other groups may have had a welfare impact.

The results in this paper differ from what would be expected based on the work of Gertler and Gruber (2002) in Indonesia. Those authors found that households are more able to protect themselves against variations in consumption expenditure due to frequent and less severe illnesses, while the converse is true for rare and serious illnesses. Given the endemic nature of malaria and hence its predictability at the study site, and since it is often a less severe illness, it might be therefore expected that having a malarious individual in the 


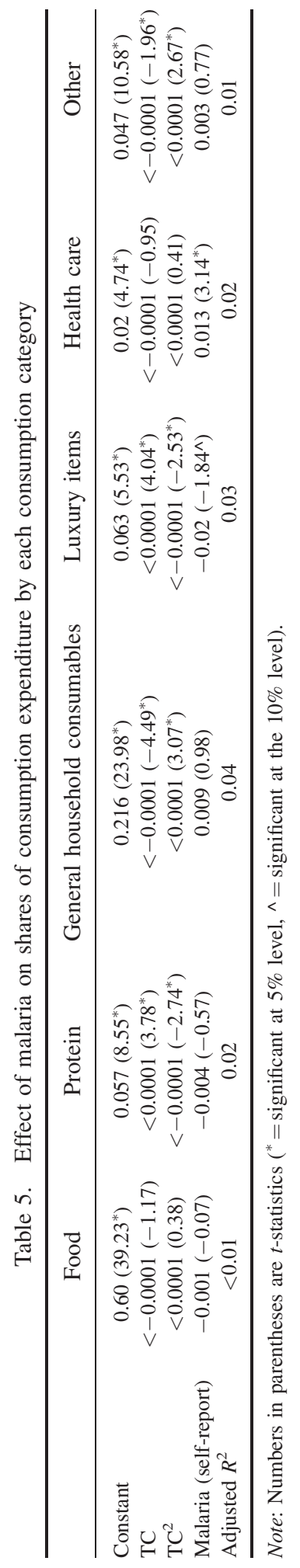


household would not affect spending in any of the six consumption categories used in this study. The evidence does not support this expectation. One reason for this may lie in the large differences in household incomes between the two studies - $\$ 740$ versus $\$ 3950$ per capita in Tanzania and Indonesia, respectively (PPP international dollars) (WHO, 2008; pp. 96-103). Further, as discussed above, 81 per cent of our sample was living on less than $\$ 1$ per day compared with 7.5 per cent in Indonesia in 2006 (WHO, 2008; pp. 96-103). It may be that households can only afford consumption insurance (saving) when their incomes pass a threshold level, with the threshold having been exceeded in Indonesia but not in Tanzania. Households' ability to smooth consumption expenditure in the face of health shocks is then compromised in Tanzania. The present study suggests that, despite malaria being endemic in the study site, it is an important health shock requiring risk mitigation strategies within households. Another reason for the difference in results may be methodological, an issue that is discussed further below.

Further research on households' coping strategies during times of illness would be useful so as to better understand the strategies employed by households at the study site. This current study did not collect sufficient information to fully understand what types of shortrun strategies households may be implementing to manage the malaria shock, for example access to credit and borrowing or to gifts. Studies in Burkina Faso (Sauerborn et al., 1996a) and in Kenya (Chuma et al., 2006) reported that strategies to cope with illness varied across households, for example poorer households had less access to credit than relatively wealthy households. Additionally, the strategies available to households may vary depending on the nature and severity of the illness; Muela et al. (2000) found that households attempting to cope with a disease perceived to be caused by witchcraft, and hence requiring treatment by a traditional healer, received greater financial support from their social networks than those requiring biomedical treatment.

\subsection{Methodological Issues: Short- Versus Long-Run}

Malaria is highly endemic in the study site and imposes a persistent and significant risk to households (Somi et al., 2007). Malaria is, however, only one risk within a broader portfolio of risks that households at the study site must manage and develop contingencies for; other potential risks include climatic variations (which affect crop success and failure), other ailments (disease and injury) and social obligations (which are also a potential source of assistance). To cope with the uncertainty associated with this portfolio of risks, households at the site will have developed long-term strategies to smooth consumption. In other settings long-run strategies have included accumulation of assets during good harvest years (Corbett, 1988) and income diversification (Dercon and Krishnan, 1996). The strategies adopted by households have been found to depend on the resources (cash, capital or human) available to them, which may provide a comparative advantage (e.g. many working age members) in some types of activities or constraints (e.g. lack of specialist skills) in others (Dercon and Krishnan, 1996). Long-run risk mitigation strategies are another area of potential future research at the study site, and Mayumana et al.'s paper in this Special Edition goes some way towards that end. It would be particularly useful to understand how long-run strategies are developed and implemented, how they evolve over time to incorporate new information and changing circumstances and to measure the outcomes of these strategies for consumption and welfare in the long-run.

The use of long-run risk mitigation strategies by households, in the study site and other settings, raises an important methodological question about the use of cross-sectional 
studies in evaluating the impact of a health shock on consumption. Assuming that longerrun strategies are at least partially effective, they should ameliorate the short-run effects of a shock. In areas with seasonal variations in the prevalence of shocks and in household liquidity, cross-sectional data collection may miss important cyclical differences in household's experiences (Litvack and Bodart, 1993; Sauerborn et al., 1996b). Additionally, and as reflected in other papers in this issue, it is impossible to measure the long-run costs and benefits of the strategies that households employ using cross-sectional data. Russell (2005) and Chuma et al. (2006) demonstrate the importance of considering the welfare effects of illness over long timeframes because the impacts of illness may emerge over time. For example, welfare (and consumption) reductions resulting from a loan may take months or even years to become apparent (Van Damme et al., 2004). The study by Gertler and Gruber (2002) on Indonesia relied upon longitudinal data and that may be a factor contributing to the differences in results between their study and the current study discussed above. Whilst longitudinal cohort studies (particularly 'case' and 'control' designs) are the ideal for the proper measurement of welfare impacts associated with shocks, they are infeasible, particularly in sub-Saharan Africa.

New frameworks for assessing the impacts of shocks such as diseases also need to be developed so that effects that are difficult to measure can be incorporated into study designs. For example, how should researchers assess the impact on welfare of a strategy such as the sale of a productive asset in order to fund treatment? The impact of this strategy in the short-run is likely to be marginal, but the sum of these marginal impacts over time may be significant. These productive assets may also act as markers of creditworthiness; their loss implies loss of access to loans and borrowing, yet this would be very difficult to quantify. There are also a group of welfare effects which can be observed at the macroeconomic but not microeconomic level (Sachs and Malaney, 2002; Malaney et al., 2004). Our current inability to quantify these costs at the microeconomic level invariably means that we are underestimating the impact of shocks such as malaria on households.

\subsection{Study Limitations}

Several limitations must be borne in mind whilst considering the findings of this study. First, the data were collected during the dry season, which, in the study site, is characterised by relatively low malaria and high household liquidity. It is likely, therefore, that the malaria and expenditure patterns reported are not indicative of household patterns across the year (see Somi et al., 2007). Data on roles and responsibilities of individual household members were not collected, for example income earners, and this limited our ability to explore the impact of a health shock on the key economic agents within the household. Various aspects of the data collection would have been subject to recall and social desirability biases, including consumption information, treatment seeking patterns (particularly about traditional healers) and their associated costs. It is likely, however, that the effects of these biases would have been random.

\section{CONCLUSIONS}

Households at the study site behave strategically when coping with the shock of a malarious/feverish individual so that they are able to fund treatment without significantly 
affecting their consumption of important items such as food. Our results suggest that, other things equal, households with at least one self-reported malarious member shift consumption away from luxury goods and into health care products. This is compatible with the hypothesis that households effectively employ strategies to smooth their consumption of food in the face of a perceived health shock.

\section{ETHICAL CLEARANCE}

The study received ethical approval from the institutional review boards of the Australian National University, Ifakara Health Research and Development Centre and the Tanzanian Medical Research Coordinating Committee.

\section{ACKNOWLEDGEMENTS}

We thank the Ifakara Health Research and Development Centre (particularly Rashid Khatib, Jensen Charles, Chrisostom Mahutanga and Berty F. Elling) and the IMPACT Tanzania project (particularly Dr S. Patrick Kachur). Thanks also to the participants at the CREHS Workshop, including Dr Kara Hanson, which was held in Kenya in June 2007, and to two anonymous referees for their constructive comments.

\section{REFERENCES}

Abdulla S, Killeen GF. 2005. MTIMBA Interim Report-Tanzania Site for INDEPTH Network (Unpublished). Ifakara Health Research and Development Centre, Dar es Salaam.

Casella G, Berger RL. 1990. Statistical Inference. Wadsworth: California.

Chima RI, Goodman CA, Mills A. 2003. The economic impact of malaria in Africa: a critical review of the evidence. Health Policy 63: 17-36.

Chuma JM, Thiede M, Molyneux CS. 2006. Rethinking the economic costs of malaria at the household level: evidence from applying a new analytical framework in rural Kenya. Malaria Journal 5: 76.

Corbett J. 1988. Famine and household coping strategies. World Development 16: 1099-1112.

Coreil J. 1983. Allocation of family resources for health care in rural Haiti. Social Science and Medicine 17: 709-719.

Deaton A, Zaidi S. 1999. Guidelines for Constructing Consumption Aggregates for Welfare Analysis. The World Bank: Princeton; 1-107.

Dercon S, Krishnan P. 1996. Income portfolios in rural Ethiopia and Tanzania: choices and constraints. Journal of Development Studies 32: 850-875.

Eriksen S, Brown J, Kelly M. 2005. The dynamics of vulnerability: locating coping strategies in Kenya and Tanzania. The Geographical Journal 171: 287-305.

Gertler P, Gruber J. 2002. Insuring consumption against illness. American Economic Review 92: 52 70.

Gove S. 1997. Integrated management of childhood illness by outpatient health workers: technical basis and overview. The WHO Working Group on Guidelines for Integrated Management of the Sick Child. Bulletin of the World Health Organization 75 (Suppl 1): 7-24. 
Government of Tanzania. 2001. Household Budget Survey. Ministry of Information Services: Dar es Salaam.

Greene WH. 2003. Econometric Analysis. Pearson Education: Upper Saddle River, New Jersey.

INDEPTH. 2002. Population and Health in Developing Countries. International Development Research Centre: Ottawa.

Litvack JI, Bodart C. 1993. User fees plus quality equals improved access to health care: results of a field experiment in Cameroon. Social Science and Medicine 37: 369-383.

Malaney P, Spielman A, Sachs J. 2004. The malaria gap. American Journal of Tropical Medicine and Hygiene 71: 141-146.

Muela SH, Mushi AK, Ribera JM. 2000. The paradox of the cost and affordability of traditional and government health services in Tanzania. Health Policy and Planning 15: 296-302.

Mugisha F, Kouyate B, Gbangou A, Sauerborn R. 2002. Examining out-of-pocket expenditure on health care in Nouna, Burkina Faso: implications for health policy. Tropical Medicine and International Health 7: 187-196.

Nyamongo IK. 2002. Health care switching behaviour of malaria patients in a Kenyan rural community. Social Science and Medicine 54: 377-386.

Roll Back Malaria. 2003. “Africa Malaria Report 2003.” Retrieved 2 May 2003.

Russell S. 2005. Illuminating cases: understanding the economic burden of illness through case study household research. Health Policy and Planning 20: 277-289.

Sachs J, Malaney P. 2002. The economic and social burden of malaria. Nature 415: 680-685.

Sauerborn R, Adams A, Hien M. 1996a. Household strategies to cope with the economic costs of illness. Social Science and Medicine 43: 291-301.

Sauerborn R, Nougtara A, Hien M, Diesfeld HJ. 1996b. Seasonal variations of household costs of illness in Burkina Faso. Social Science and Medicine 43: 281-290.

Somi MF, Butler JRG, Vahid F, Njau JD, Kachur SP, Abdulla S. 2007. Economic burden of malaria in rural Tanzania: variations by socioeconomic status and season. Tropical Medicine and International Health 12: 1139-1147.

Van Damme W, Van Leemput L, Por I, Hardeman W, Meessen B. 2004. Out-of-pocket health expenditure and debt in poor households: evidence from Cambodia. Tropical Medicine and International Health 9: 273-280.

World Health Organization. 2008. World Health Statistics 2008. WHO: Geneva.

Worrall E, Basu S, Hanson K. 2005. Is malaria a disease of poverty? A review of the literature. Tropical Medicine and International Health 10: 1047-1059. 